\title{
Autoshaping in the rat: Interposing delays between responses and food
}

\author{
C. M. LOCURTO \\ College of the Holy Cross, Worcester, Massachusetts 01610 \\ HEATHER DUNCAN and H. S. TERRACE \\ Columbia University, New York, New York 10027 \\ and \\ JOHN GIBBON \\ Columbia University, New York, New York 10027 \\ and the New York Psychiatric Institute, New York, New York 10032
}

\begin{abstract}
Rats were exposed to an autoshaping procedure in which each lever-contact or leverpress delayed trial offset and, hence, food delivery. Yoked subjects received identical trial-food pairings as did delay subjects. This procedure was studied at two delay values $(2.5$ and $10.0 \mathrm{sec})$ in experimentally naive rats and those which had previously received 25 sessions of autoshaping. The delay procedure retarded the acquisition of autoshaped responding in naive subjects and reduced responding for experienced subjects. Yoked subjects responded at higher levels than did delay subjects throughout training.
\end{abstract}

The significance of autoshaping derives in part from the similarity between this phenomenon and other instances of classically conditioned response systems (see, Hearst \& Jenkins, 1974, for a comprehensive review). This correspondence is founded upon a variety of findings including the identity observed in the topography of autoshaped responses and consummatory behavior (e.g., Jenkins \& Moore, 1973) and the success in controlling autoshaped responses by manipulating the predictiveness of the conditioned stimulus (e.g., Gamzu \& Williams, 1973; Gibbon, Baldock, Locurto, Gold, \& Terrace, 1977; Gibbon, Locurto, \& Terrace, 1975).

Perhaps the most important basis for emphasizing the Pavlovian nature of autoshaping may be traced to studies of omission training, a procedure in which autoshaped responding has the effect of cancelling reinforcer delivery. The persistence of responding despite this negative response-reinforcer relation is consistent with the conclusion that responding is controlled principally by the positive stimulus-reinforcer relation that is present on those trials in which no responses occur. To date, several studies of omission training (i.e., negative automaintenance) using pigeons have indicated that keypecking may be engendered

Portions of this work were presented at the annual meeting of the Eastern Psychological Association, Boston, April 1977. Requests for reprints should be addressed ts the first author, Department of Psychology, College of the Holy Cross, Worcester, Massachusetts 01610. and maintained at substantial levels despite the imposition of the omission contingency (e.g., Schwartz \& Williams, 1972a, 1972b; Williams \& Williams 1969; Woodard, Ballinger, \& Bitterman, 1974).

There can be little doubt that the data generated using the omission procedure deserve careful attention. However, these findings also raise two issues. For one, the conclusion that omission training supports significant levels of keypecking in the pigeon has not been unequivocally confirmed (e.g., Barrera, 1974; Hursh, Navarick, \& Fantino, 1974; Powell \& Kelly, 1976). In species other than the pigeon, it is evident that omission training may suppress responding as effectively as a random-control procedure or simple extinction [e.g., in rats, Locurto, Terrace, \& Gibbon (1976, 1978), cf. Atnip (1977) and Stiers \& Silberberg (1974); in the squirrel monkey, Gamzu \& Schwam (1974), Schwam \& Gamzu (1975); in the guinea pig, Poling \& Poling (1978); see Schwartz \& Gamzu (1977) for a review].

The use of the omission procedure presents interpretative problems as well. These difficulties derive from the use of omission training as an analytic tool to understand the role played by Pavlovian (i.e., stimulus-reinforcer) and instrumental (i.e., responsereinforcer) relations in the standard autoshaping procedure wherein reinforcers are scheduled irrespective of responding. An instance of continued responding under an omission contingency is compatible with, but does not force, the conclusion that responsereinforcer relations play but a minor role in auto- 
shaping. It may be that either Pavlovian or instrumental relations are capable of supporting an autoshaped response. Perhaps as one relation is removed the other becomes predominent (Jenkins, 1977).

Conversely, if responding is significantly reduced or eliminated during omission training, it does not indicate that Pavlovian relations are ineffectual in autoshaping. It may only reveal that in this instance the negative response-reinforcer relation was stronger than were stimulus-reinforcer pairings. In this sense, it must be remembered that omission training contains a response contingency not present in autoshaping (e.g., Boakes, 1977; cf. Deich \& Wasserman, 1977).

It is also possible to interpret these response reductions. solely in Pavlovian terms. During omission training, the stimuli associated with signal-contact responding become paired with nonreinforcement. As a result, a subject's signal-directed behavior is reduced and attention is redirected to other stimuli in the chamber. In turn, these stimuli are paired with reinforcement and come to control directed (i.e., autoshaped) behavior. In this sense, reductions in signal-directed responding may be regarded as Pavlovian discrimination learning (Dickinson \& Mackintosh, 1978). That is, the consequence of the omission contingency is to bring the subject into contact with other stimuli predictive of reinforcement.

These considerations suggest that no single procedure serves as the unconfounded assay of Pavlovian or instrumental control (see, for example, Hearst, 1975). It may be most efficacious to evaluate the results drawn from a family of strategies in addition to omission training in an effort to understand the

\section{AUTOSHAPING: TRIAL OFFSET DELAY PROCEDURE}

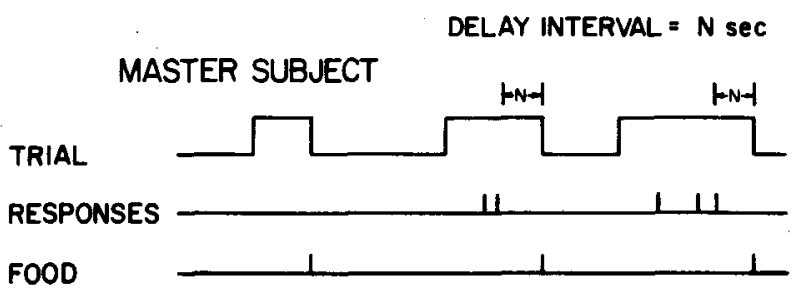

YOKED SUBJECT

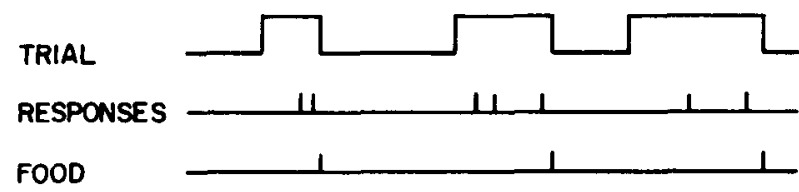

TIME

Figure 1. The trial-offset-delay procedure for master and yoked subjects. Each lever-contact or leverpress by the master subject delays the offset of the trial (and food delivery) by $n$ sec for both subjects. Responses by the yoked subject have no effect on trial duration. respective influence of these contingencies in autoshaping. One such alternative strategy, a trial-offset delay (TOD) procedure, is outlined in Figure 1. In the "master" condition, any response during a trial interrupts the trial timer for $\mathrm{n}$ sec, thereby insuring that any response is separated from the end of the trial, and hence food delivery, by at least $\mathrm{n}$ sec. This condition is evaluated with respect to a yoked treatment in which the temporal relations between trials and food are identical to the master condition. However, for yoked subjects, responses may occur in close conjunction to food delivery. This procedure, then, equates two subjects in terms of stimulusreinforcer pairings while allowing relations between responses and reinforcers to differ between them. [For a comparable procedure using pigeons, see Schwartz and Gamzu's (1977) description of an unpublished study by Williams.]

The present study examined the effects of this procedure at two values of the delay interval (n), 2.5 and $10.0 \mathrm{sec}$, in experimentally naive rats and in rats exposed to 25 sessions of fixed-trial autoshaping prior to placement on the delay procedure.

\section{METHOD}

\section{Subjects}

The subjects were 28 male hooded rats, approximately 125 days old at the start of training. They were maintained at $70 \% \pm 3 \%$ of their free-feeding weights and were fed supplementary food in their home cages following each experimental session to maintain these weights.

\section{Apparatus}

Two identical test chambers were used, each a modified ice chest (80-quart capacity). The subject's portion of the chamber was $24 \mathrm{~cm}$ wide, $29.5 \mathrm{~cm}$ long, and $34 \mathrm{~cm}$ high. The test panel consisted of a feeder dish located in the middle of the panel at floor level. A retractable rodent lever (Camden Instruments, Inc.) was housed $4 \mathrm{~cm}$ above the floor and $7 \mathrm{~cm}$ to the right of the dish. A force of approximately $15 \mathrm{~g}(.15 \mathrm{~N})$ was necessary to depress the lever sufficiently to register a press. The lever protruded $2.5 \mathrm{~cm}$ into the chamber when inserted. Contacts with the lever in each chamber were recorded via drinkometer circuits. The reinforcer was a 97-mg standard rat pellet (P. J. Noyes, Co.). A 50-W houselight remained on during each session.

\section{Procedure}

The subjects were divided into 14 pairs, and members of each pair were randomly assigned either to the delay or to the yoked condition. Each subject was then trained to eat reliably from the feeder dish. Feeder training consisted of three consecutive sessions during which 50 pellets were delivered on a variable-time (VT) 20 -sec schedule. All VT schedules were drawn from the distribution suggested by Fleshler and Hoffman (1962). For the initial session, subjects were given experimenter-delivered pellets on an approximate VT 20 -sec schedule until eating was judged to be regular. Thereafter, all pellets were delivered according to the VT schedule.

On the day following the third feeder training session, all pairs were given the first of seven operant-level sessions. Beginning with the first session, paired subjects were run concurrently in their respective chambers. Each session consisted of 25 trials with no reinforcers. Trials were defined as the $15-\mathrm{sec}$ insertion of the lever into the chamber. ${ }^{1}$ Responses by either subject had no effect on trial duration during operant-level sessions. Intertrial intervals 


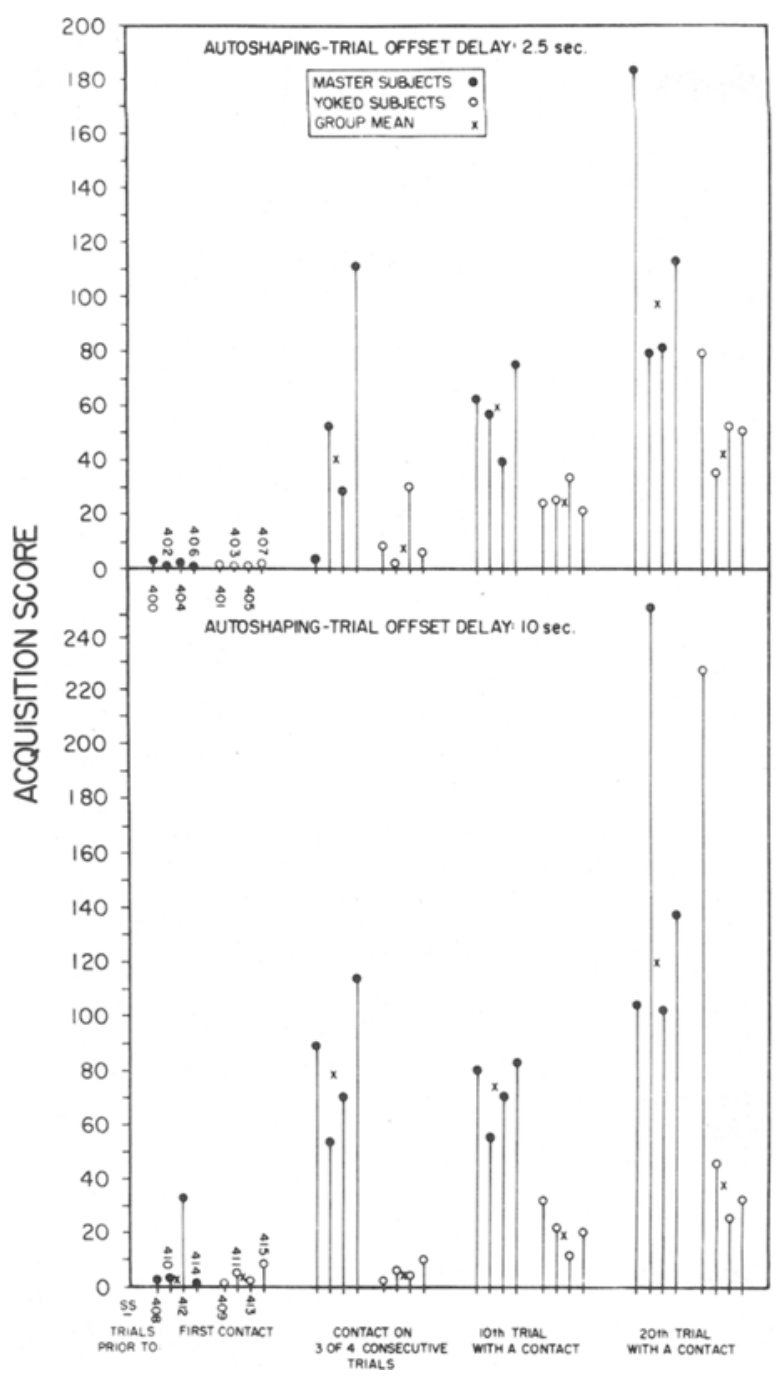

Figure 2. The number of trials prior to reaching several acquisition criteria. The criteria are specified along the abscissa. Individual subjects are represented by a three-digit number along the abscissa. Each subject occupies the same ordinal position for each acquisition measure.

during all phases of training were arranged using a VT 60 -sec schedule.

Following the seventh operant-level session, eight pairs were placed on the TOD procedure, four at the $2.5-\mathrm{sec}$ delay and four at the 10.0-sec delay interval. The six remaining pairs began 25 sessions of fixed-trial autoshaping in which a reinforcer was delivered at the end of each 15 -sec trial. Following the 25 th session, these pairs began the TOD procedure with three pairs assigned to each delay interval.

During TOD training, 25 trials per session were programmed for $15 \mathrm{sec}$ if no lever-contact or leverpress was emitted by the master subject. Either type or response by the master interrupted the trial timer for $\mathrm{n} \sec (2.5$ or $10.0 \mathrm{sec})$. Each trial terminated with delivery of a reinforcer.

Sessions were generally conducted 5 days a week.

\section{RESULTS}

For both experimentally naive subjects and those with prior autoshaping training, master subjects pro- duced lower levels of responding than yoked subjects. In addition, for master subjects, the 10.0-sec delay interval resulted in lower levels of maintained responding than did the 2.5-sec delay. Similar differences were not observed for yoked subjects.

Figure 2 shows the acquisition scores for experimentally naive subjects. Acquisition was defined as the number of lever-food pairings prior to reaching several criteria, each of which is specified along the abscissa. Master and yoked subjects did not differ in either the 2.5 -sec or the $10.0-\mathrm{sec}$ TOD groups with respect to the number of trials prior to the first levercontact. This lack of difference is to be expected in that the delay contingency is not sampled by the master subject until the first contact. Thereafter, however, a reliable pattern of differences emerged, with master subjects reaching each acquisition criterion more slowly than did yoked subjects $(p<.05$ for each acquisition measure with two exceptions: $\mathrm{p}=.25$ for contacts on three of four consecutive trials at $2.5 \mathrm{sec} ; \mathrm{p}=.13$ for the $20^{\text {th }}$ trial with a contact at $10.0 \mathrm{sec}){ }^{2}$ Indeed, there were few overlaps between master and yoked pairs on any acquisition measure.

The response probability of each naive subject during each session at both TOD values is given in Figure 3 . The probability of a response was defined as the proportion of trials with at least one levercontact. It is apparent that the differences between master and yoked subjects observed in acquisition persisted during extended training. The response probability of yoked subjects, averaged across all sessions,

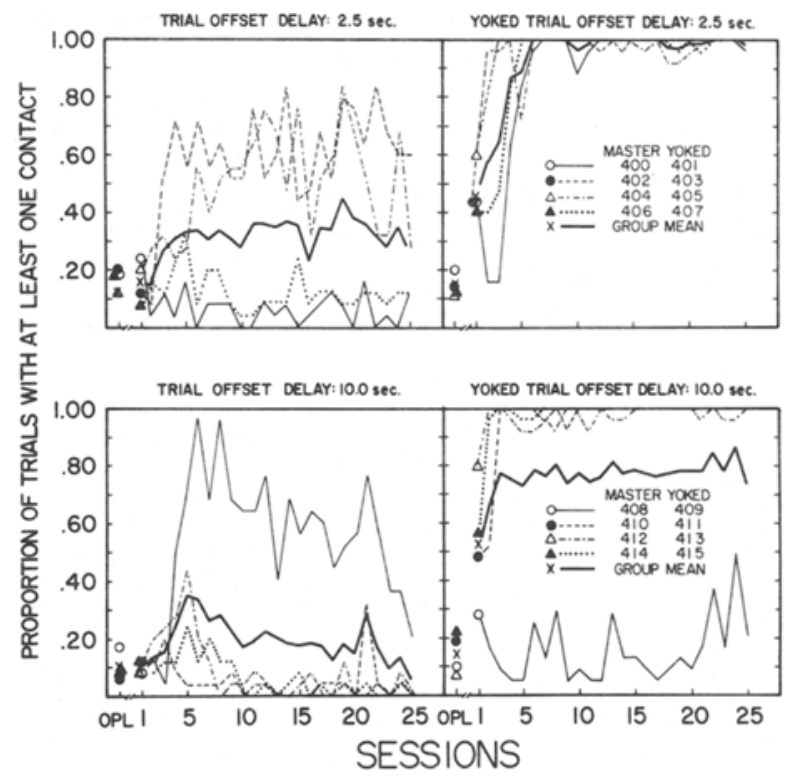

Figure 3. The probability of a response, defined as the proportion of trials with at least one lever-contact, for experimentally naive master and yoked subjects. Points to the left of Session 1, labeled "OPL," indicate the mean response probability during the last five operant-level sessions. 
exceeded that of masters at each delay value $(p<$ $.05)$. At the 2.5-sec interval, two master subjects (400 and 406) responded at probabilities which did not exceed their operant levels, while two other subjects produced intermediate response probabilities. In contrast, each yoked subject reached the 1.0 level of responding within seven sessions. In the 10.0-sec TOD group, three master subjects responded at nearzero levels throughout the last 15 sessions, while their yoked partners produced response probabilities of 1.0 , beginning with the fourth session. One pair (408 and 409) produced a different pattern of maintained responding, with the master subject attaining high levels early in training, followed by decreases over the final 18 sessions. The opposite pattern was evident for the yoked partner of this master subject. One may also note a tendency for master subjects at the 10.0-sec interval to maintain lower response probabilities than master subjects at the 2.5 -sec interval $(p=.10)$. Comparable differences were not apparent for yoked subjects.

The differences observed in naive subjects were also apparent for subjects which received 25 sessions of autoshaping prior to the TOD procedure. In Figure 4, the response probabilities for each of these subjects is shown during the 25 sessions of TOD training. It can been seen that all subjects were responding at a probability of approximately 1.0 when placed on the TOD procedure. During TOD training, the responding of yoked subjects exceeded that of masters at each delay value $(p<.05)$. Indeed, the response probability of yoked subjects appeared to be uniformly unaffected throughout TOD training, with the exception of one subject during two sessions (304, Sessions 13-14).

In Table 1, the obtained trial durations for all subjects are presented. For naive subjects, with the exception of one pair (408-409), these durations did not differ markedly from the programmed value of $15 \mathrm{sec}$ during any portion of training. However, experienced subjects obtained durations early in training that were, on the average, nearly twice as long as those
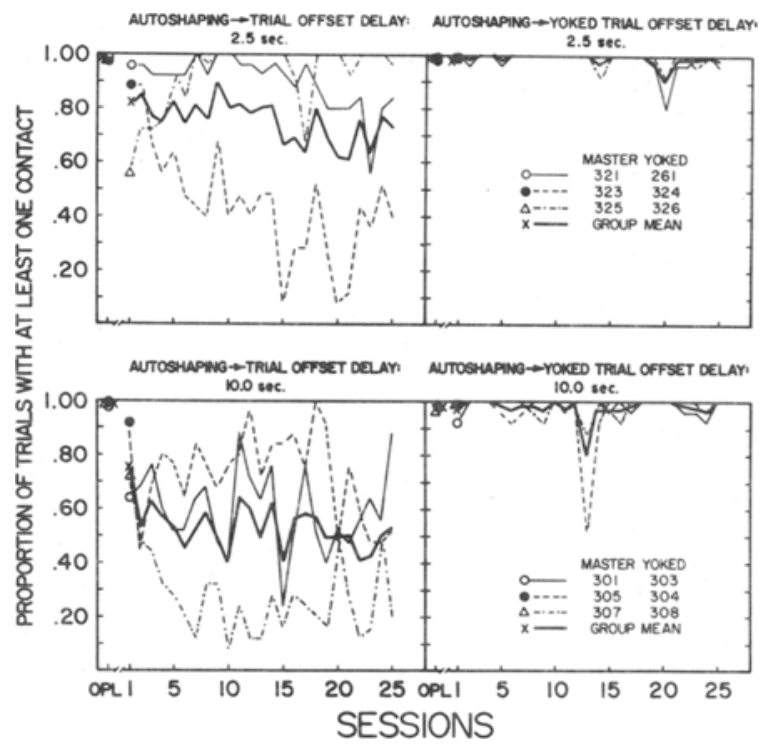

Figure 4. The probability of a response, defined as the proportion of trials with at least one lever-contact, for master and yoked subjects with prior fixed-trial autoshaping training. Points to the left of Session 1. labeled " $B$," indicate the mean response probability during the last five baseline (autoshaping) sessions.

produced by naive subjects. During the later stages of training, each experienced pair obtained trials of reduced duration.

\section{DISCUSSION}

Autoshaping has rapidly come to serve as a cornerstone of those theoretical approaches that emphasize the role played by Pavlovian relations in conditioned behavior (e.g., Dickinson \& Mackintosh, 1978; Hearst \& Jenkins, 1974). While these positions do not represent a unified framework, they share a common assumption that stimulus-reinforcer relations are sufficient to engender and maintain substantial levels of autoshaped responding. Lajoie and Bindra (1976)

Table 1

Mean Obtained Trial Duration (in Seconds) for All Subjects

\begin{tabular}{|c|c|c|c|c|c|}
\hline \multicolumn{3}{|c|}{ Experimentally Naive Subjects } & \multicolumn{3}{|c|}{ Subjects With Prior Autoshaping } \\
\hline \multirow{2}{*}{$\begin{array}{c}\text { Subject } \\
\text { Pair }\end{array}$} & \multicolumn{2}{|c|}{ Sessions } & \multirow{2}{*}{$\begin{array}{c}\text { Subject } \\
\text { Pair }\end{array}$} & \multicolumn{2}{|c|}{ Sessions } \\
\hline & $1-5$ & $21-25$ & & $1-5$ & $21-25$ \\
\hline \multicolumn{6}{|c|}{ Delay Interval $=2.5 \mathrm{sec}$} \\
\hline $\begin{array}{l}400-401 \\
402-403 \\
404-405 \\
406-407\end{array}$ & $\begin{array}{l}15.81 \\
17.33 \\
16.42 \\
15.92\end{array}$ & $\begin{array}{l}15.96 \\
19.41 \\
16.83 \\
15.80\end{array}$ & $\begin{array}{l}321-261 \\
323-324 \\
325-326\end{array}$ & $\begin{array}{l}34.44 \\
25.63 \\
27.42\end{array}$ & $\begin{array}{l}21.76 \\
18.28 \\
25.27\end{array}$ \\
\hline \multicolumn{6}{|c|}{ Delay Interval $=10.0 \mathrm{sec}$} \\
\hline $\begin{array}{l}408-409 \\
410-411 \\
412-413 \\
414-415\end{array}$ & $\begin{array}{l}19.91 \\
16.94 \\
19.84 \\
16.65\end{array}$ & $\begin{array}{l}22.71 \\
16.50 \\
15.15 \\
15.45\end{array}$ & $\begin{array}{l}301-303 \\
305-304 \\
307-308\end{array}$ & $\begin{array}{l}33.54 \\
41.72 \\
28.93\end{array}$ & $\begin{array}{l}25.40 \\
35.66 \\
20.85\end{array}$ \\
\hline
\end{tabular}


offer the most elaborated statement of this view in arguing that Pavlovian contingencies predominate not only in autoshaping, but also in many instances of supposed instrumental learning. From this perspective, instrumental relations are important only insofar as they direct the subject's attention to appropriate stimuli in the test environment (e.g., response manipulandum), thereby insuring that these stimuli become effectively linked with the reinforcer. That is, responsereinforcer pairings set the occasion for Pavlovian relations to take effect (see also Moore, 1973).

In the present study, the levels of responding observed in naive and experienced yoked subjects indicate quite clearly that the obtained stimulusreinforcer relations were sufficient to support nearperfect response probabilities. Yet, five of the eight naive master subjects did not exceed their operant level of responding. These results would not appear to be easily accommodated by those interpretations which evaluate autoshaping exclusively in Pavlovian terms. To preserve this approach, one might adopt the interpretation outlined previously with respect to omission training: low response probabilities in either procedure may be seen as a result of Pavlovian discrimination training in which the omission or TOD contingency has the effect of redirecting the subject to other features of the test environment.

However, it must be recognized that these data also conform to an interpretation centered upon instrumental relations. Indeed, if one considers the delay procedure as a discrete-trial analog of the differentialreinforcement-of-other-behavior (DRO) schedule, the present findings have their counterpart in the response suppression typically observed in that freeoperant procedure (e.g., Uhl, 1973; Zeiler, 1971). To evaluate the present findings, it may be helpful to consider analyses of delayed reinforcement in instrumental paradigms which have relied upon the conditioning of competing responses during the delay interval (e.g., Spence, 1956). Accordingly, the TOD procedure may be viewed as one which arranged for the reinforcement of behaviors which were incompatible with those signal-directed responses controlled by the Pavlovian relation. These data, then, represent the interesting case in which response-reinforcer relations, once sampled, render Pavlovian relations relatively ineffective in controlling behavior (see, also, Locurto et al., 1976). Contemporary research has emphasized those instances in which stimulus-reinforcer relations disrupt or otherwise influence ongoing instrumental behavior (Gamzu \& Williams, 1973; Hearst \& Jenkins, 1974; LoLordo, McMillan, \& Riley, 1974). Much less attention has been directed to the complementary situation wherein instrumental relations may affect Pavlovian control.

Given these interpretative possibilities, it would appear to be a matter of theoretical preference whether one wishes to speak of competing responses or Pavlovian discrimination. These uncertainties, in turn, lead to the question of whether any family of procedures may be identified which might be used as an assay of Pavlovian-instrumental control. That is, might one construct a testing procedure much in the manner as that proposed to assess inhibitory stimulus control (e.g., Hearst, Besley, \& Farthing, 1970)?

Unfortunately, it appears that procedures other than omission training and the TOD also suffer from interpretative difficulties. As an example, the differential/nondifferential procedure studied by Gamzu and Williams $(1971,1973)$ in pigeons has often been cited as a critical test of instrumental influence (Lajoie \& Bindra, 1976; Schwartz \& Gamzu, 1977). In their differential procedure, reinforcers were scheduled to occur with a probability of $.03 / \mathrm{sec}$ only during autoshaping trials (8.6 sec of key illumination). In the nondifferential case, reinforcers occurred with equal probability during the trial and intertrial interval, which averaged $30 \mathrm{sec}$. Substantial response rates were maintained only in the differential procedure (see also, Boakes, 1977, for comparable results using rats).

These results have been viewed as supporting a Pavlovian interpretation of autoshaping. For, while the nondifferential procedure eliminates the predictive relation between the conditioned stimulus and reinforcer, it might be expected to have little effect upon any adventitious instrumental relations which occur during the conditioned stimulus. These relations would appear to be equally possible in both the differential and nondifferential procedure. Accordingly, if instrumental relations are important, it is difficult to see why adding reinforcers to the intertrial interval should reduce responding.

However, it is possible that response-reinforcer pairings are involved in this procedure. In the nondifferential condition, behaviors incompatible with keypecking may be established through adventitious reinforcement during the intertrial interval. These behaviors may continue to occur and be reinforced during conditioned stimulus presentations, thereby interfering with keypecking (see Deich \& Wasserman, 1977, Footnote 2; Jenkins, 1977). That is, the nondifferential procedure does not only eliminate the predictiveness of the conditioned stimulus; it may also support the development of responses incompatible with keypecking.

An additional strategy has consisted of blocking the occurrence of response-reinforcer pairings during the initial portion of training by placing a barrier in front of the response key (Moore, 1973). The acquisition of keypecking is subsequently tested with the barrier removed. The procedure has been studied most extensively by Wasserman, Hunter, Gutowski, and Bader (1975). During pretraining with the barrier 
present, different groups of young chicks received either forward pairings of the conditioned stimulus and a thermal reinforcer or one of several control conditions, including random pairings and a reinforceronly treatment. During subsequent autoshaping training, keypecking was engendered more rapidly and maintained at higher levels by subjects in the forwardpairing group.

These results have been taken as evidence of the primacy of stimulus-reinforcer pairings in autoshaping, as compared to the adventitious reinforcement of keypecking. Yet, this manipulation is far from convincing. During pretraining in the forward-pairing condition, it is possible that key-directed behaviors (e.g., orientations, approaches, pecks) were reinforced. To the extent that these behaviors serve as the nonindependent precursors of keypecking, instrumental factors may be implicated in subsequent keypecking [compare Peden, Brown, \& Hearst (1977) with Wessells (1974)]. Relevant to this point is the observation of Wasserman et al. (1975) that, during pretraining in the forward-pairing condition, subjects frequently approached the barrier and pecked towards the response key. As a corollary, in the control conditions, it is possible that behaviors incompatible with subsequent keypecking were adventitiously reinforced [cf., however, Browne (1976), for a related procedure in which access to the reinforcer is blocked during pretraining].

A final experimental strategy which bears upon the distinction between Pavlovian and instrumental influence in autoshaping concerns the correspondence between the topography of conditioned (i.e., autoshaped) and unconditioned responses. It has been assumed that if instrumental relations are influential, then the form of the conditioned response should be independent of the form of the unconditioned response, depending instead upon which topography was adventitiously reinforced. Conversely, from a Pavlovian perspective, the form of the conditioned response might be expected to closely resemble that of the unconditioned response [cf. Jenkins and Moore (1973); for a review of this argument as applied to other classically conditioned response systems, see Mackintosh, (1974)].

There are two problems with this strategy. First, the empirical evidence is conflicting. In the case of the pigeon's keypeck to a visual stimulus using food or water reinforcers, the topographies of the conditioned and unconditioned responses are virtually identical (Jenkins \& Moore, 1973). A more equivocal case is found in the chick's pecking to a visual stimulus using a thermal reinforcer (Wasserman, 1973). There appears to be divergence in the form of these responses in the squirrel monkey's leverpress using a food reinforcer (Gamzu \& Schwam, 1974;
Schwam \& Gamzu, 1975) and in the rat's autoshaped response to the presentation of another rat predicting food delivery (Timberlake \& Grant, 1975).

Moreover, topographical similarity does not invariably predict Pavlovian control, at least as assessed by the omission procedure. As noted earlier, the pigeon's keypeck with both food and water as the reinforcer bears close topographical similarity to the unconditioned response form. Yet, the keypeck appears to be far more sensitive to an omission contingency using water than to one using food [compare Woodruff and Williams (1976) to Williams and Williams (1969)]. These considerations suggest that the existence of a topographical correspondence between conditioned and unconditioned responses does not rule out the possibility that response probability is influenced by instrumental relations.

In sum, it is apparent that these procedures do not combine to serve as a critical test of Pavlovian or instrumental influence (cf. however, Gamzu \& Schwam, 1974; Lajoie \& Bindra, 1976). Indeed, perhaps the most salient feature of the data derived from these procedures is the range of conclusions that may be supported using them. This variability may indicate that the assumption underlying their use, that Pavlovian and instrumental influence may be experimentally partitoned, is misguided. If so, there is a growing family of alternatives available (e.g., Bolles, 1975).

Perhaps it would be most efficacious to adopt an "interactive" position wherein Pavlovian and instrumental relations are seen as independent variables which conjointly determine the outcome of any conditioning procedure. An instructive example derived from this position has been presented by Woodruff, Connor, Gamzu, and Williams (1978). Using pigeons, these authors studied a free-operant multiple schedule in which food reinforcement was confined to one component with extinction always associated with the second component. The effects of the Pavlovian relation were studied by varying component duration (see, Gibbon et al. 1977). The instrumental contingency was altered by manipulating the percentage of reinforcers delivered after a response-produced delay interval. It was noted that variations in both relations influenced response rate. Most important, the effects of either relation depended upon the value of the other: one relation had maximum effect when the second relation was relatively weak.

It must be recognized that this position does not permit one to specify whether Pavlovian or instrumental relations represent fundamentally different underlying mechanisms. Yet, it may offer the opportunity for more comprehensive identification of the manner by which these two relations mutually determine performance. 


\section{REFERENCES}

AtNip, G. W. Stimulus- and response-reinforcer contingencies in autoshaping, operant, classical, and omission training procedures in rats. Journal of the Experimental Analysis of Behavior, $1977,28,59-69$.

Barrera, F. J. Centrifugal selection of signal directed pecking. Journal of the Experimental Analysis of Behavior, 1974, 22, 341-355.

Bonkes, R. A. Performance on learning to associate a stimulus with positive reinforcement. In H. Davis \& H. M. B. Hurwitz (Eds.), Operant-Pavlovian interactions. Hillsdale, N.J: Erlbaum, 1977.

Bolles, R. C. Learning theory. New York: Holt, Rinehart \& Winston, 1975.

Browne, M. P. The role of primary reinforcement and overt movement in autoshaping in the pigeon. Animal Learning \& Behavior, 1976, 4, 287-292.

Deich, J. D., \& Wasserman, E. A. Rate and temporal pattern of key-pecking under autoshaping and omission schedules of reinforcement. Journal of the Experimental Analysis of Behav. ior, 1977, 27, 399-405.

Dickinson, A., \& Mackintosh, N. J. Classical conditioning in animals. In M. R. Rosenzweig \& L. W. Porter (Eds.), Annual review of psychology. Palo Alto, Calif: Annual Reviews, 1978.

Fleshler, M., \& Hoffman, H. S. A progression for generating variable interval schedules. Journal of the Experimental Analysis of Behavior, 1962, 5, 529-530.

Gamzu, E, \& Schwam, E. Autoshaping and automaintenance of a key-press response in squirrel monkeys. Journal of the Experimental Analysis of Behavior, 1974, 21, 361-371.

Gamzu, E., \& Williams, D. R. Classical conditioning of a complex skeletal response. Science, 1971, 171, 923-925.

Gamzu, E., \& Williams, D. R. Associative factors underlying the pigeon's key pecking in autoshaping procedures. Journal of the Experimental Analysis of Behavior, 1973, 19, 225-232.

Gibbon, J., Baldock, M. D., Locurto, C., Gold, L., \& Terrace, H. S. Trial and intertrial durations in autoshaping. Journal of Experimental Psychology: Animal Behavior Processes, 1977, 3, 264-285.

Gibbon, J., Locurto, C., \& Terrace, H. S. Signal-food contingency and signal frequency in a continuous trials autoshaping paradigm. Animal Learning \& Behavior, 1975, 3, 317-324.

Hearsi, E. The classical-instrumental distinction: Reflexes, voluntary behavior, and categories of associative learning. In W. K. Estes (Ed.), Handbook of learning and cognitive processes: Conditioning and behavior theory (Vol. 2). Hillsdale, N.J: Erlbaum, 1975.

Hearst, E., Besley, S., \& Farthing, G. W. Inhibition and the stimulus control of operant behavior. Journal of the Experimental Analysis of Behavior, 1970, 14, 373-409.

Hearst, E., \& Jenkins, H, M. Sign tracking: The stimulusreinforcer relation and directed action. Austin, Tex: Psychonomic Society, 1974.

Hursh, S. R., Navarick, D. J., \& Fantine, E. Automaintenance: The role of reinforcement. Journal of the Experimental Analysis of Behavior, 1974, 21, 112-124.

JENKins, H. M. Sensitivity of different response systems to stimulus-reinforcer and response-reinforcer relations. In $\mathrm{H}$. Davis \& H. M. B. Hurwitz (Eds.), Operant-Pavlovian interactions. Hillsdale, N.J: Erlbaum, 1977.

Jenkins, H. M., \& Moore, B. R. The form of the auto-shaped response with food or water reinforcers. Journal of the Experimental Analysis of Behavior, 1973, 20, 163-181.

LAJoje, J., \& Bindra, D. An interpretation of autoshaping and related phenomenon in terms of stimulus incentive contingencies alone. Canadian Journal of Psychology, 1976, 30, 157-173.

Locurto, C., Terrace, H. S., \& Gibion, J. Autoshaping, ran- dom control, and omission training in the rat. Journal of the Experimental Analysis of Behavior, 1976, 26, 451-462.

Locurto, C. M.,. Terrace, H. S., \& Gibbon, J. Omission training (negative automaintenance) in the rat: Effects of trial of fset. Bulletin of the Psychonomic Society, 1978, 12, 11-14.

Lolordo, V. M., McMillan, J. C., \& Riley, A. L. The effects upon food-reinforced pecking and treadle-pressing of auditory and visual signals for response-independent food. Learning and Motivation, 1974, 5, 24-41.

MAck INTOSH, N. J. The psychology of animal learning. London: Academic Press, 1974.

Moone, B. R. The role of directed Pavlovian reactions in simple instrumental learning in the pigeon. In R. A. Hinde \& J. Stevenson-Hinde (Eds.), Constraints on learning. New York: Academic Press, 1973.

Peden, B. F., Browne, M. P., \& Hearst, E. Persistent approaches to a signal for food despite food omission for approaching. Journal of Experimental Psychology: Animal Behavior Processes, 1977, 3, 377-399.

Poling, A., \& Poling, T. Automaintenance in guinea pigs: Effects of feeding regimen and omission training. Journal of the Experimental Analysis of Behavior, 1978, 30, 37-46.

Powell, R. W., \& Kelly, W. Responding under positive and negative response contingencies in pigeons and crows. Journat of the Experimental Analysis of Behavior, 1976, 25, 219-225

Schwam, E., \& Gamzu, E. Constraints on autoshaping in the squirrel monkey: Stimulus dimension and response topography. Bulletin of the Psychonomic Society, 1975, 5, 369-372.

Schwartz, B., \& Gamzu, E. Pavlovian control of operant behav. ior: An analysis of autoshaping and its implications for operant conditioning. In W. K. Honig \& J. E. R. Staddon (Eds.), Handbook of operant behavior. Englewood Cliffs, N.J: Prentice-Hall, 1977

Scinartz, B., \& Williams, D. R. The role of the responsereinforcer contingency in negative auto-maintenance. Journal of the Experimental Analysis of Behavior, 1972, 71, 351-357. (a)

SchwarTz, B., \& Williams, D. R. Two different kinds of key peck in the pigeon: Some properties of responses maintained by negative and positive response-reinforcer contingencies. Journal of the Experimental Analysis of Behavior, 1972, 18, 201-216. (b)

Sifgel, S. Nonparametric statistics for the behavioral sciences. New York: McGraw-Hill, 1956.

SPENCE, K. Behavior theory and conditioning. New Haven: Yale University Press, 1956.

Stiers, M., \& Silberberg, A. Autoshaping and automaintenance of lever-contact responses in rats. Journal of the Experimental Analysis of Behavior, 1974, 22, 497-506.

Timberlake, W., \& Grant, D. L. Auto-shaping rats to the presentation of another rat predicting food. Science, 1975, 190, 690-692.

UHL, C. N. Eliminating behavior with omission and extinction after varying amounts of training. Animal Learning \& Behavior, 1973, 1, 237-240.

Wasserman, E. A. Pavlovian conditioning with heat reinforcement produces stimulus-directed pecking in chicks. Science, 1973, 181, 875-877

Wasserman, E. A., Hunter, N. B., Gutowski, K. A., \& BADER, S. A. Autoshaping chicks with heat reinforcement. The role of stimulus-reinforcer and response-reinforcer relations. Journal of Experimental Psychology: Animal Behavior Processes, 1975, 1, 158-169.

Wessells, M. G. The effects of reinforcement upon the prepecking behaviors of pigeons in the autoshaping experiment. Journal of the Experimental Analysis of Behavior, 1974, 21, $125 \cdot 144$.

Williams, D. R., \& Williams, H. Automaintenance in the pigeon: Sustained pecking despite contingent nonreinforcement. 
Journal of the Experimental Analysis of Behavior, 1969, 12, $511-520$.

Woodard, W. T., Ballinger, J. C., \& Bitterman, M. E. Autoshaping: Further study of "negative automaintenance." Journal of the Experimental Analysis of Behavior, 1974, 22, 47-52.

WoodrufF, G., \& Williams, D. R. The associative relation underlying autoshaping in the pigeon. Journal of the Experimental Analysis of Behavior, 1976, 26, 1-13.

Woodruff, G., Connor, N., Gamzu, E., \& Williams, D. R. Associative interaction: Joint control of key pecking by stimulusreinforcer and response-reinforcer relationstips. Journal of the Experimental Analysis of Behavior, 1977, 28, 133-144.

ZEILER, M. Eliminating behavior with reinforcement. Journal of the Experimental Analysis of Behavior, 1971, 16, 401-405.

\section{NOTES}

1. Contacts with the lever were not recorded during the first $.50 \mathrm{sec}$ of each trial in order to eliminate the possiblity of the subject contacting the lever during its insertion into the chamber.

2. All statistical tests were conducted using the Mann-Whitney $\mathrm{U}$ test. Master/yoked differences were tested using the randomization test for matched pairs (Siegel, 1956).

(Received for publication September 5, 1978; revision accepted April 18, 1979.) 